NPM1 mutations in a large cohort of young adult patients with acute myeloid leukemia. Blood 2008; 111: 2776-2784.

$8 \mathrm{Im}$ AP, Sehgal AR, Carroll MP, Smith BD, Tefferi A, Johnson DE et al. DNMT3A and IDH mutations in acute myeloid leukemia and other myeloid malignancies: associations with prognosis and potential treatment strategies. Leukemia 2014; 28: 1774-1783.

9 DiNardo CD, Ravandi F, Agresta S, Konopleva M, Takahashi K, Kadia T et al. Characteristics, clinical outcome, and prognostic significance of IDH mutations in AML. Am J Hematol 2015; 90: 732-736.

10 Rakheja D, Konoplev S, Medeiros L, Chen W. IDH mutations in acute myeloid leukemia. Hum Pathol 2012; 43: 1541-1551.

11 Boissel N, Nibourel O, Renneville A, Gardin C, Reman O, Contentin N et al. Prognostic impact of isocitrate dehydrogenase enzyme isoforms 1 and 2 mutations in acute myeloid leukemia: a study by the Acute Leukemia French Association group. J Clin Oncol 2010; 28: 3717-3723.

12 Green CL, Evans CM, Zhao L, Hills RK, Burnett AK, Linch DC et al. The prognostic significance of IDH2 mutations in AML depends on the location of the mutation. Blood 2011; 118: 409-412.

13 Arber DA, Orazi A, Hasserjian R, Thiele J, Borowitz MJ, Le Beau MM et al. The 2016 revision to the World Health Organization classification of myeloid neoplasms and acute leukemia. Blood 2016; 127: 2391-2405.

14 Patel KP, Ravandi F, Ma D, Paladugu A, Barkoh BA, Medeiros LJ et al. Acute myeloid leukemia with IDH1 or IDH2 mutation: frequency and clinicopathologic features. Am J Clin Pathol 2011; 135: 35-45.

15 Chang E, Ganguly S, Rajkhowa T, Gocke CD, Levis M, Konig H. The combination of FLT3 and DNA methyltransferase inhibition is synergistically cytotoxic to FLT3/ITD acute myeloid leukemia cells. Leukemia 2016; 30: 1025-1032.

\title{
OPEN
}

\section{Sustained deep molecular responses in patients switched to nilotinib due to persistent $B C R-A B L 1$ on imatinib: final ENESTcmr randomized trial results}

Leukemia (2017) 31, 2529-2531; doi:10.1038/leu.2017.247

For patients with chronic myeloid leukemia in chronic phase (CML$\mathrm{CP})$, treatment with a BCR-ABL1 tyrosine kinase inhibitor (TKI), such as imatinib or nilotinib, can result in high response rates and nearnormal life expectancies. ${ }^{1-3}$ Although most patients treated with imatinib achieve a complete cytogenetic response (CCyR) and many achieve a major molecular response (MMR; BCR-ABL $1 \leqslant 0.1 \%$ on the International Scale $\left.\left(B C R-A B L 1^{15}\right)\right), \mathrm{MR}^{4}\left(B C R-A B L 1^{15} \leqslant 0.01 \%\right)$, or $\mathrm{MR}^{4.5}$ $\left(B C R-A B L 1^{15} \leqslant 0.0032 \%\right){ }^{4-10}$ results from the Evaluating Nilotinib Efficacy and Safety in Clinical Trials-Newly Diagnosed Patients (ENESTnd) study showed that frontline nilotinib therapy results in higher response rates than frontline imatinib therapy.,10

ENEST-Complete Molecular Remission (ENESTcmr) was a 48month, open-label, randomized, phase 3 study designed to investigate whether patients with CCyR but persistent minimal residual disease (MRD) on long-term imatinib could achieve deeper molecular responses by switching to nilotinib $400 \mathrm{mg}$ twice daily vs remaining on imatinib. The study design and methods were previously described in detail ${ }^{11}$ and are summarized in the Supplemental Methods. The study was conducted in accordance with the Declaration of Helsinki. An independent ethics committee or institutional review board at each center approved the protocol. All patients provided written informed consent before randomization. The trial was registered at www.ClinicalTrials.gov (NCT00760877).

Results from the first 24 months of follow-up were previously reported and showed that patients randomized to nilotinib achieved higher rates of MMR and deeper molecular responses than did patients randomized to continue imatinib. ${ }^{11}$ Per the study protocol, patients in the imatinib arm with detectable $B C R-A B L 1$ at 24 months were allowed to cross over to nilotinib. Here we report updated results from ENESTcmr based on 48 months of treatment for patients who completed the study, including an evaluation of the impact of crossover on patients' molecular responses.
Of 104 patients randomized to nilotinib $400 \mathrm{mg}$ twice daily, 59 (56.7\%) completed 48 months of nilotinib treatment on study and 45 (43.3\%) discontinued early (Supplementary Figure 1). Of 103 patients randomized to imatinib, 41 (39.8\%) completed 48 months of imatinib treatment on study, 16 (15.5\%) discontinued without crossing over to nilotinib, and $46(44.7 \%)$ crossed over to nilotinib (due to detectable $B C R-A B L 1$ after 24 months of study treatment $(n=41)$, imatinib failure $(n=3)$, or loss of undetectable $B C R-A B L 1$ $(n=2))$; after crossing over, 36 patients completed the study on nilotinib and 10 discontinued early. The most common reason for early discontinuation of study treatment in both arms was adverse events (AEs; nilotinib, $n=19$; imatinib, $n=12$ (5 prior to crossover and 7 after crossover); Supplementary Figure 2).

Overall, 56 of 104 patients (53.8\%) in the nilotinib arm achieved $\mathrm{MR}^{4.5}$ by 48 months; among patients in the imatinib arm, 46 of $103(44.7 \%)$ achieved $\mathrm{MR}^{4.5}$ by 48 months, but 13 of these patients achieved $\mathrm{MR}^{4.5}$ only after crossover to nilotinib. The Kaplan-Meier-estimated median time to $\mathrm{MR}^{4.5}$ was $24(95 \% \mathrm{Cl}$, 14.8-47.5) months in the nilotinib arm and was not reached by 48 months in the imatinib arm (Figure 1). Among patients without $\mathrm{MR}^{4.5}$ at baseline, 51 of $98(52.0 \%)$ in the nilotinib arm and 40 of 96

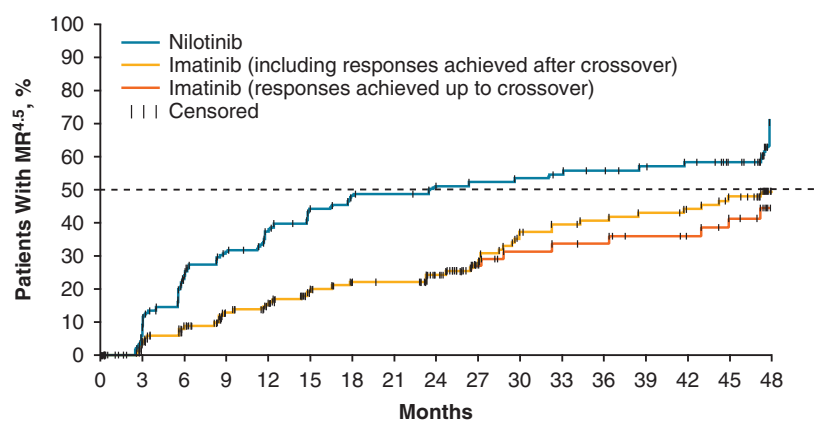

Figure 1. Time to Achievement of First $M R^{4.5}$ (ITT population). ITT, intention-to-treat; $M R^{4.5}, B C R-A B L 1 \leqslant 0.0032 \%$ on the International Scale. 
Table 1. Achievement of $\mathrm{MR}^{4.5}$ according to response status at baseline and crossover

\begin{tabular}{|c|c|c|c|}
\hline & $\begin{array}{c}\text { Nilotinib } \\
\text { arm }\end{array}$ & $\begin{array}{c}\text { Imatinib } \\
\text { arm }\end{array}$ & P-value ${ }^{a}$ \\
\hline $\begin{array}{l}\text { All patients } \\
\text { Achieved } \mathrm{MR}^{4.5} \text { by } 48 \text { months }\end{array}$ & $n=104$ & $n=103$ & \\
\hline ITT, $n(\%)$ & $56(53.8)$ & $46(44.7)$ & 0.1766 \\
\hline Up to crossover, $n$ (\%) & $56(53.8)$ & $33(32.0)$ & 0.0011 \\
\hline After crossover, $\mathrm{n} / \mathrm{m}(\%)^{\mathrm{b}}$ & NA & $20 / 46(43.5)^{c}$ & NA \\
\hline $\begin{array}{l}\text { Patients without MMR at baseline } \\
\text { Achieved MR } \\
4.5 \text { by } 48 \text { months }\end{array}$ & $n=24$ & $n=28$ & \\
\hline ITT, $n$ (\%) & $8(33.3)$ & $6(21.4)$ & 0.4279 \\
\hline Up to crossover, $n$ (\%) & $8(33.3)$ & $1(3.6)$ & 0.0055 \\
\hline After crossover, n/m (\%) ${ }^{d}$ & NA & $5 / 17(29.4)^{\mathrm{e}}$ & NA \\
\hline $\begin{array}{l}\text { Patients with } M M R \text { but without } \\
M R^{4.5} \text { at baseline }\end{array}$ & $n=74$ & $n=68$ & \\
\hline \multicolumn{4}{|l|}{ Achieved $\mathrm{MR}^{4.5}$ by 48 months } \\
\hline ITT, $n(\%)$ & $43(58.1)$ & $34(50.0)$ & 0.2273 \\
\hline Up to crossover, $n(\%)$ & $43(58.1)$ & $26(38.2)$ & 0.0084 \\
\hline After crossover, $n / m(\%)^{f}$ & NA & $14 / 28(50.0)^{g}$ & NA \\
\hline
\end{tabular}

Abbreviations: ITT, intention-to-treat; MMR, major molecular response; $M R^{4.5}, B C R-A B L 1 \leqslant 0.0032 \%$ on the International Scale. ${ }^{a} P$-values are nominal. No multiplicity adjustments were made; therefore, statistical interpretation should be made with caution. $P$-values were obtained using the Cochran-Mantel-Haenszel test. ${ }^{\mathrm{b}}$ Denominator is the number of patients who crossed over. ${ }^{\mathrm{C}} \mathrm{A}$ total of 20 patients achieved $\mathrm{MR}^{4.5}$ after crossover, including 13 who achieved $\mathrm{MR}^{4.5}$ for the first time on nilotinib, 4 who achieved $\mathrm{MR}^{4.5}$ on imatinib and maintained the response on nilotinib and 3 who regained $M^{4.5}$ on nilotinib after losing the response prior to crossover. ${ }^{\mathrm{d}}$ Denominator is the number of patients without MMR at baseline who crossed over. ${ }^{e}$ Of the 11 patients without MMR at baseline who did not cross over, 1 achieved $\mathrm{MR}^{4.5}$ on imatinib and was not eligible to cross over; the other 10 patients were eligible to cross over but did not, and none of these achieved $M^{4.5}$. fDenominator is the number of patients with MMR but without $M^{4.5}$ at baseline who crossed over. ${ }^{9}$ Of the 68 patients with MMR but without $\mathrm{MR}^{4.5}$ at baseline, 28 crossed over and 40 did not cross over. Twenty of the 40 patients who did not cross over achieved MR ${ }^{4.5}$ on imatinib by the end of the study. Fourteen of the 28 patients who crossed over achieved MR $R^{4.5}$ by the end of the study, including 10 patients who achieved $\mathrm{MR}^{4.5}$ for the first time after crossover and 4 patients who achieved $\mathrm{MR}^{4.5}$ before and after crossover.

(41.7\%) in the imatinib arm achieved $\mathrm{MR}^{4.5}$ by 48 months (Supplementary Figure 3). Thirty-eight of 46 patients who crossed over from imatinib to nilotinib had not achieved $\mathrm{MR}^{4.5}$ on imatinib prior to crossover; of these, 13 achieved a first $\mathrm{MR}^{4.5}$ on nilotinib. Of the eight patients who achieved $M^{4.5}$ prior to crossover (including 4 with $\mathrm{MR}^{4.5}$ detected at the time of crossover), seven achieved or maintained $\mathrm{MR}^{4.5}$ on nilotinib. Similarly, among the subsets of patients without MMR at baseline or with MMR but without $M R^{4.5}$ at baseline, more patients achieved $M^{4.5}$ on study with nilotinib than with imatinib (Table 1).

Among patients who crossed over to nilotinib at 24 months and remained on nilotinib with an evaluable molecular assessment at 48 months, $B C R-A B L 1^{\text {IS }}$ levels decreased rapidly following crossover, despite having previously remained relatively stable during imatinib therapy (Supplementary Figure 4). Median (25th-75th percentile) $B C R-A B L 1^{15}$ levels decreased from $0.0205 \%(0.0074-$ $0.1841 \%)$ at 24 months to $0.0086 \%(0.0012-0.0266 \%)$ at 48 months in patients who were eligible to cross over at 24 months, crossed over and remained on nilotinib at 48 months. In contrast, $B C R-A B L 7^{\text {IS }}$ levels in patients who remained on imatinib through month 48 despite being eligible to cross over at 24 months were relatively stable; the median (25th-75th percentile) $B C R-A B L 1^{\text {IS }}$ level in these patients was $0.0086 \%(0.0055-0.0247 \%)$ at 24 months and $0.0075 \%(0.0028-0.0159 \%)$ at 48 months.

No patient in either arm progressed to accelerated phase/blast crisis by 48 months. Three patients in each arm died (none due to
$\mathrm{CML}$ ). In the nilotinib arm, two patients discontinued study treatment due to death (one each due to myocardial infarction (on study day 178) and cardiopulmonary failure (day 780)), and one patient died $>28$ days after study drug discontinuation (due to liver failure (day $1439, \approx 8$ months after discontinuation)). In the imatinib arm, one patient discontinued study treatment due to death (due to peritoneal carcinomatosis (day 1334)), and two patients died $>28$ days after study drug discontinuation (one each due to prostate cancer (day 736, $\approx 18$ months after discontinuation) and metastatic non-small cell lung cancer (day 1127, $\approx 2$ months after discontinuation)). No patient who crossed over from imatinib to nilotinib died on study treatment or after study drug discontinuation. The estimated rate of overall survival at 48 months was $96.6 \%$ (95\% Cl, 89.7-98.9\%) in the nilotinib arm and 96.9\% (95\% Cl, 90.6$99.0 \%$ ) in the imatinib arm (regardless of crossover).

Safety results were consistent with the previous analysis. ${ }^{11}$ Additionally, with $\approx 2$ years of nilotinib treatment after crossover, the safety profile of nilotinib $400 \mathrm{mg}$ twice daily in patients who crossed over was comparable to that observed during the first 24 months of study treatment in patients randomized to the nilotinib arm (Supplementary Table 1). Cardiovascular events (CVEs, including ischemic heart disease (IHD), ischemic cerebrovascular events (ICVEs), and peripheral artery disease (PAD)) occurring during study treatment were reported in 13 patients in the nilotinib arm (12.9\% (IHD, $n=4$; ICVE, $n=4$; PAD, $n=7)$ ), two patients in the imatinib arm prior to crossover (1.9\% (IHD, $n=1$; ICVE, $n=1))$, and three patients after crossover to nilotinib $(6.5 \%$ (IHD, $n=1$; ICVE, $n=1$; PAD, $n=1)$ ). Of the 18 patients in both arms with CVEs during study treatment, 13 had $\geqslant 1$ known preexisting cardiovascular risk factor (including age $\geqslant 65$ years $(n=9)$, history of hypertension ( $n=4$, all receiving treatment), history of diabetes mellitus ( $n=2$, both receiving treatment), and/or history of hypercholesterolemia ( $n=1$, untreated)) and/or a prior CVE $(n=3$, including one patient with a history of transient ischemic attack; one patient with a history of thrombosis, deep vein thrombosis, peripheral vascular disorder and transient ischemic attack; and one patient with a history of Raynaud phenomenon) at enrollment. AEs of pancreatitis were reported in $3(3.0 \%)$ and 0 patients in the nilotinib and imatinib arms, respectively; pancreatitis was not reported after crossover in any patient.

Although this study was not powered to evaluate differences in long-term outcomes between the study arms, the results reported here demonstrate that switching to nilotinib therapy may enable some patients with persistent MRD on long-term imatinib to achieve further reductions in $B C R-A B L 1$ levels, resulting in increased rates of deep molecular response. Moreover, as achievement of a sustained deep molecular response is a key eligibility criterion for attempting treatment-free remission (TFR), ${ }^{12}$ these results suggest that switch to nilotinib may enable some patients to become eligible for TFR and support further investigation of TFR following nilotinib therapy. Importantly, however, not all patients were able to achieve deep molecular responses after switching to nilotinib treatment, and some discontinued nilotinib due to AEs. Thus, both the potential for improved efficacy with nilotinib and the potential for new AEs, including CVEs, should be considered when evaluating whether to switch treatment for a patient. Nonetheless, the observed dynamics of changes in $B C R-A B L 1$ transcript levels after patients in the imatinib arm crossed over to nilotinib provide a further illustration of the benefits of switching to nilotinib. BCR-ABL1 levels rapidly decreased following crossover to nilotinib, enabling many patients to achieve $\mathrm{MR}^{4.5}$, whereas patients who were eligible to cross over for persistent detectable MRD at 24 months (by which time such patients had received imatinib for a total duration of $\geqslant 4-$ 5 years, including treatment prior to study enrollment ${ }^{11}$ ) but remained on imatinib had relatively stable transcript levels between 24 and 48 months. These results suggest that most patients have stable $B C R-A B L 1$ levels following long-term imatinib therapy and are unlikely to achieve further substantial reductions in transcript levels 
with continued imatinib therapy. Overall, results from ENESTcmr support switching to nilotinib for some patients with persistent MRD after long-term imatinib.

\section{CONFLICT OF INTEREST}

The authors declare the following relationships: TPH: Novartis (research funding, honoraria, board of directors or advisory board membership), Bristol-Myers Squibb (research funding, honoraria, board of directors or advisory board membership), Ariad (research funding, honoraria, board of directors or advisory board membership); BL: Novartis (consultancy, honoraria, speakers bureau, board of directors or advisory board membership); FC: Novartis (honoraria, speakers bureau), Ariad (speakers bureau), BristolMyers Squibb (speakers bureau); APS: Novartis (honoraria), Bristol-Myers Squibb (honoraria), Pfizer (honoraria), Celgene (honoraria); F-XM: Bristol-Myers Squibb (consultancy, honoraria), Novartis (consultancy, research funding, honoraria), Pfizer (honoraria), Ariad (honoraria); DR: Novartis (honoraria), Ariad (honoraria), Bristol-Myers Squibb (honoraria), Pfizer (honoraria); AG-B: Novartis (honoraria), Amgen (honoraria), Bristol-Myers Squibb (consultancy, honoraria), Pfizer (honoraria); SA: Novartis (employment); TG: Novartis (employment); DD: Novartis (employment); SB: Novartis (research funding, honoraria, speakers bureau, board of directors or advisory board membership), Qiagen (honoraria, board of directors or advisory board membership), Ariad (research funding); JHL: Novartis (consultancy, research funding, honoraria, board of directors or advisory board membership), Ariad (consultancy, research funding, honoraria, board of directors or advisory board membership), Bristol-Myers Squibb (consultancy, research funding, honoraria, board of directors or advisory board membership), Pfizer (consultancy, research funding, honoraria, board of directors or advisory board membership). The remaining authors declare no conflict of interest.

\section{ACKNOWLEDGEMENTS}

The ENESTcmr study and the work presented here were sponsored and funded by Novartis Pharmaceuticals Corporation. Financial support for medical editorial assistance was provided by Novartis Pharmaceuticals Corporation. We thank Karen Kaluza, PhD, and Jonathan Morgan, PhD, of ArticulateScience LLC, for medical editorial assistance with this manuscript.

\section{AUTHOR CONTRIBUTIONS}

Study conception and design: TPH, BL, NS, SK-R, SA, JHL. Provision of study materials and patients: TPH, BL, FC, NS, RP, APS, NCDC, PED-L, F-XM, DR, AG-B, SK-R, IB, JHL. Data collection: TPH, RP, APS, AG-B, SK-R, DD, JHL. Data analysis and interpretation: TPH, APS, SA, DD, SB, JHL. All authors drafted, reviewed, and approved the manuscript.

TP Hughes ${ }^{1}$, B Leber ${ }^{2}$, F Cervantes ${ }^{3}$, N Spector ${ }^{4}$, R Pasquini ${ }^{5}$, NCD Clementino ${ }^{6}$, AP Schwarer ${ }^{7}$, PE Dorlhiac-Llacer ${ }^{8}$, F-X Mahon $^{9}$, D Rea ${ }^{10}$, A Guerci-Bresler ${ }^{11}$, S Kamel-Reid ${ }^{12}$, I Bendit ${ }^{13}$, S Acharya ${ }^{14}$, T Glynos $^{15}$, D Dalal ${ }^{15}$, S Branford ${ }^{16}$ and JH Lipton ${ }^{17}$

${ }^{1}$ Division of Haematology, SA Pathology and South Australian Health and Medical Research Institute, University of Adelaide, Adelaide,

South Australia, Australia;

${ }^{2}$ Clinical Pathology, McMaster University, Hamilton, Ontario, Canada;

${ }^{3}$ Department of Hematology, Hospital Clinic, IDIBAPS, University of

Barcelona, Barcelona, Spain;

${ }^{4}$ Departamento de Clínica Médica/FM, Universidade Federal do Rio de Janeiro, Rio de Janeiro, Brazil;

${ }^{5}$ Division of Hematology and Medical Oncology, Federal University

of Paraná, Curitiba, Brazil;

${ }^{6}$ Hospital Das Clinicas da UFMG, Belo Horizonte, Brazil;

${ }^{7}$ Department of Hematology, Alfred Hospital, Melbourne, Victoria, Australia;

${ }^{8}$ Department of Hematology, Hospital das Clinicas FMUSP, São Paulo, Brazil;

${ }^{9}$ Laboratoire Hématopoïse Leucémique et Cible Thérapeutique, Inserm U1035, Université Victor Ségalen, Bordeaux, France;

${ }^{10}$ Unité de Thérapie Cellulaire et Clinique Transfusionnelle, Service des Maladies du Sang et EA3518, Hôpital Saint-Louis, Paris, France;

${ }^{11}$ Department of Hematology, Brabois Hospital, Vandoeuvre-lèsNancy, Vandoeuvre, France; ${ }^{12}$ Clinical Laboratory Genetics, Genome Diagnostics, University Health Network, Toronto General Hospital, Toronto, Ontario, Canada;

${ }^{13}$ Hematology Unit, Faculty of Medicine, University of São Paulo, São Paulo, Brazil;

${ }^{14}$ Novartis Healthcare Pvt Ltd, Hyderabad, India; ${ }^{15}$ Novartis Pharmaceuticals Corporation, East Hanover, NJ, USA;

${ }^{16}$ Leukaemia Unit, Centre for Cancer Biology, SA Pathology, University of South Australia and University of Adelaide, Adelaide, South Australia, Australia and

${ }^{17}$ Blood and Marrow Transplant Service, Princess Margaret Cancer Centre, University of Toronto, Toronto, Ontario, Canada E-mail: tim.hughes@sahmri.com

\section{REFERENCES}

1 Baccarani M, Deininger MW, Rosti G, Hochhaus A, Soverini S, Apperley JF et al. European LeukemiaNet recommendations for the management of chronic myeloid leukemia: 2013. Blood 2013; 122: 872-884.

2 National Comprehensive Cancer Network 2017. NCCN clinical practice guidelines in oncology: chronic myeloid leukemia. 2017; v2.2017.

3 Gambacorti-Passerini C, Antolini L, Mahon FX, Guilhot F, Deininger M, Fava C et al. Multicenter independent assessment of outcomes in chronic myeloid leukemia patients treated with imatinib. J Natl Cancer Inst 2011; 103: 553-561.

4 Kantarjian HM, Talpaz M, O'Brien S, Jones D, Giles F, Garcia-Manero G et al. Survival benefit with imatinib mesylate versus interferon-alpha-based regimens in newly diagnosed chronic-phase chronic myelogenous leukemia. Blood 2006; 108: 1835-1840.

5 Druker BJ, Guilhot F, O'Brien SG, Gathmann I, Kantarjian H, Gattermann N et al. Five-year follow-up of patients receiving imatinib for chronic myeloid leukemia. $N$ Engl J Med 2006; 355: 2408-2417.

6 de Lavallade H, Apperley JF, Khorashad JS, Milojkovic D, Reid AG, Bua M et al. Imatinib for newly diagnosed patients with chronic myeloid leukemia: incidence of sustained responses in an intention-to-treat analysis. $J$ Clin Oncol 2008; 26: 3358-3363.

7 Kalmanti L, Saussele S, Lauseker M, Müller MC, Dietz CT, Heinrich L et al. Safety and efficacy of imatinib in CML over a period of 10 years: data from the randomized CML-study IV. Leukemia 2015; 29: 1123-1132.

8 Branford S, Seymour JF, Grigg A, Arthur C, Rudzki Z, Lynch K et al. BCR-ABL messenger RNA levels continue to decline in patients with chronic phase chronic myeloid leukemia treated with imatinib for more than 5 years and approximately half of all first-line treated patients have stable undetectable BCR-ABL using strict sensitivity criteria. Clin Cancer Res 2007; 13: 7080-7085.

9 Saglio G, Kim DW, Issaragrisil S, le Coutre P, Etienne G, Lobo C et al. Nilotinib versus imatinib for newly diagnosed chronic myeloid leukemia. $N$ Engl J Med 2010; 362: 2251-2259.

10 Hochhaus A, Saglio G, Hughes TP, Larson RA, Kim DW, Issaragrisil S et al. Longterm benefits and risks of frontline nilotinib vs imatinib for chronic myeloid leukemia in chronic phase: 5-year update of the randomized ENESTnd trial. Leukemia 2016; 30: 1044-1054.

11 Hughes TP, Lipton JH, Spector N, Cervantes F, Pasquini R, Clementino NCD et al. Deep molecular responses achieved in patients with CML-CP who are switched to nilotinib after long-term imatinib. Blood 2014; 124: 729-736.

12 Hughes TP, Ross DM. Moving treatment-free remission into mainstream clinical practice in CML. Blood 2016; 128: 17-23.

\section{(i)}

This work is licensed under a Creative Commons Attribution 4.0 International License. The images or other third party material in this article are included in the article's Creative Commons license, unless indicated otherwise in the credit line; if the material is not included under the Creative Commons license, users will need to obtain permission from the license holder to reproduce the material. To view a copy of this license, visit http://creativecommons.org/licenses/ by/4.0/@

(c) The Author(s) 2017

Supplementary Information accompanies this paper on the Leukemia website (http://www.nature.com/leu) 